|| Print ISSN: 2589-7837 || Online ISSN: 2581-3935 ||

International Journal of Medical Science and Diagnosis Research (IJMSDR)

Available Online at www.ijmsdr.com

NLM (National Library of Medicine ID: 101738824)

Original Research Article

Volume 5, Issue 1; January: 2021; Page No. 31-34

\title{
CAREGIVERS BURDEN OF PATIENTS WITH ALCOHOL USE DISORDER: COMPARISON BETWEEN SPOUSE \& OTHER CAREGIVERS
}

\author{
Dr. Atul Bhardwaj ${ }^{1}$, Dr. Vaibhav Dubey ${ }^{2}$, Dr. Mitali Soni Loya ${ }^{3}$ \\ ${ }^{1}$ Department of Psychiatry, Bundelkhand Medical College, Sagar \\ ${ }^{2,3}$ Department of Psychiatry, People's College of Medical Sciences and Research Centre, Bhopal, Madhya \\ Pradesh, India
}

Conflicts of Interest: Nil

Corresponding author: Dr. Atul Bhardwaj

DOI: https://doi.org/10.32553/ijmsdr.v5i1.745

\begin{abstract}
:
Background: Caregivers are individuals who carry the responsibility for the physical and emotional needs of another, who is incapable of self-care. Burden is described by the presence of issues, difficulties, or adverse events which affect the lives of the psychiatric patient's family or friends in other words their caregivers. Identification of caregivers who are burdened by the caregiving experience is significant for the prevention of problems associated with caregiving especially in case of spouses. The Caregiver Burden Inventory (CBI), a well-known measure of care giving burden with a distinct domain structure is used to study burden of the caregivers of patients with alcohol use disorder.

Purpose: Alcohol dependency is a "family disease." Alcohol dependence affects both the person \& others around them in terms of jobs and social instability. The other aspects affecting the Family includes physical and emotional pain and financial strain that have a major effect on the lives o significant others.

A significant research emphasis remains on the mental and physical health of caregivers, theirsocial support system, coping mechanisms, and levels of stress and burden. The purpose of this study is to analyse and compare the burden of patients with alcohol use disorder using CBI between spouses and other caregivers

Methods: A total of 100 primary caregivers of patients with alcohol use disorder completed survey questionnaires. Caregiving burden was measured by the CBI. The diagnosis of alcohol use disorder was made in accordance to the DSM 5 criteria.

Results: Severe Burden was seen in the spouse caregivers as compared to other relations.

Conclusion: The findings provide evidence that spouse of patients with alcohol use disorder experienced severe burden as compared to others.
\end{abstract}

Keywords: Alcohol use disorder, Caregivers, Zarit Burden Inventory, Severity of burden

\section{Introduction:}

Caregivers are individuals who carry the responsibility for the physical and emotional needs of another, who is incapable of self-care. Addiction to alcohol is a major risk to an individual and society but the maximum strain of the disorder is borne by the family. The importance of care increases in patients with mental illnesses where the family stands to top the list. This stands true in India because of numerous reasons like dependence on the family, and inadequate number of mental health experts. Alcohol use disorder is a major problem at both social and personal threats. According to the Global Status Report on Alcohol,
Alcohol dependence accounts for 1.4 percent of the global disease burden.

The mental and physical health of caregivers, their social support system, coping strategies, and levels of stress and burden remain a major focus of research, as evidenced by a number of recent literature reviews and meta-analyses. The positive aspects of caregiving experiences are receiving increased attention as well. Some caregivers derive positive meaning from the caregiving role, whereas most of them suffer from negative effects of it.

\subsection{Alcohol use disorder:}

When compared to depression and schizophrenia, alcohol dependence is less commonly regarded as 
mental illness and the patients are held responsible for their conditions. This stigma of alcoholism aggravates negative effects on social behaviour and social environment hindering patients from seeking social as well as medical support. To overcome this stigma, it has become necessary to understand alcohol dependence as a legit health condition or a 'brain disease'.

'Alcohol use disorder' meets the criteria under the class of substance-related and addictive disorders in the fifth edition of the American Psychiatric Association (APA) Diagnostic and Statistical Manual of Mental Disorders: DSM-5 (2013). In DSM-5, the categories of 'alcohol abuse' and 'alcohol dependence' were combined to define a single disorder on a continuum from mild to severe.

The epidemic of alcohol abuse is a relapsing illness in India. According to the report Ministry of social justice and empowerment, National Drug Dependence Treatment Centre (NDDTC) and All India Institute of Medical Sciences (AIIMS), of New Delhi India named "Magnitude of Substance Use in India", 2019, the abuse of various psychoactive substances such as alcohol, cannabis and opioids has been observed in India for centuries. The report suggested the current dimension of extent and pattern of psychoactive substance use.

\subsection{An overview of the burden as a concept:}

In recent research studies burden has commonly been used as an indicator, however, burden used in caregiver research, lacks an adequate operational sense. Therefore, in order to determine its characteristics, need for further clarification of the concept is required. It has become all the more relevant as family involvement is a must for patience with alcohol dependence.

\section{Purpose:}

The mental and physical health of caregivers, their social support system, coping strategies, and levels of stress and burden remain a major focus of research. The purpose of this study is to examine \& compare the burden between spouse and other caregivers of patients with alcohol use disorder using CBI.

\section{Material and Method:}

In our study a cross sectional study conducted in the department of Psychiatry, Peoples Hospital and Research Centre, Bhopal. Institutional Ethical committee approved the study. All caregivers of patients with Alcohol use disorder were explained the nature of the study in the language suitable for them. Informed consent was obtained for further assessment. This study was carried out over a period of one and a half year.

\subsection{Study Sample:}

In our study a total of 100 first degree relatives of Alcohol use disorder patients were selected.

\subsection{Scale applied:}

The care giving Burden Inventory developed by Canadian researchers is being adapted across nations. The authors of the instrument stress the importance of using a multidimensional measurement of burden with separate scores for each dimension as opposed to global or uni-dimensional scores. The Inventory comprises 24 closed questions divided into five dimensions: time-dependence, developmental, physical, social and emotional burden. There are five items in each dimension except for physical burden, which has four items dedicated to it. Each item is given a score between 0 (not at all descriptive) and 4 (very descriptive), where higher scores indicate greater caregiver burden; there are no cut-off points for classifying burden.

\subsection{Data Collection Procedure:}

The questions were read to the patients as written and in the order indicated. The caregivers were provided with the available response categories given for each question. When a response option was chosen they were probed during the initial questions to be sure that they had selected the most accurate response. If responses were ambiguous or evasive, the question and response were repeated, asking caregiver to choose the best answer. The answers were then recorded carefully on a scale given in the questionnaire.

\subsection{Statistical Analysis:}

The data obtained was compiled systematically and then subjected to statistical analysis. A master table was prepared and total data was subdivided and distributed meaningfully and presented as tables along with charts. All the Data Analysis was done using SPSS (Statistical Package for the Social Sciences) version 23.0 IBM.

\section{Results:}


Table 1: comparison of cbi score between wife and others

\begin{tabular}{|c|c|c|c|c|c|c|c|}
\hline S.NO. & CBI (DIMENSIONS) & & WIFE & OTHERS & $\mathbf{t}$ & df & $\mathbf{p}$ \\
\hline 1 & TIME DEPENDENCY & $\begin{array}{l}\text { RANGE } \\
\text { MEAN(S.D.) }\end{array}$ & $\begin{array}{l}7-18 \\
13.07(2.91)\end{array}$ & $\begin{array}{l}6-17 \\
12.61(2.93)\end{array}$ & 0.764 & 98 & $.045^{*}$ \\
\hline 3 & EMOTIONAL DEPENDENCE & $\begin{array}{l}\text { RANGE } \\
\text { MEAN(S.D.) }\end{array}$ & $\begin{array}{l}7-18 \\
12.11(2.36) \\
\end{array}$ & $\begin{array}{l}5-14 \\
10.45(2.18) \\
\end{array}$ & 3.58 & 98 & 0.001* \\
\hline 4 & SOCIAL RELATIONSHIP & $\begin{array}{l}\text { RANGE } \\
\text { MEAN(S.D.) }\end{array}$ & $\begin{array}{l}8-18 \\
13.97(2.71) \\
\end{array}$ & $\begin{array}{l}7-18 \\
13.19(2.42) \\
\end{array}$ & 1.494 & 98 & 0.148 \\
\hline 6 & TOTAL CBI & $\begin{array}{l}\text { RANGE } \\
\text { MEAN(S.D.) }\end{array}$ & $\begin{array}{l}43-84 \\
66.15(10.5)\end{array}$ & $\begin{array}{l}37-89 \\
60.38(10.8)\end{array}$ & 2.62 & 98 & 0.010* \\
\hline
\end{tabular}

Table 1 demonstrates the comparison of all the dimensions of CBI for wife caregivers and others. It was found that time dependency had a significant difference for wife and other $(\mathrm{p}=.045, \mathrm{t}=.764, \mathrm{df}=98)$. There is no significant difference in burden of development in case of wife or others as $(\mathrm{p}=.236$, $\mathrm{t}=1.195, \mathrm{df}=98$ ). The significant difference between wife and others exists for emotional dependence $(\mathrm{p}=.001, \mathrm{t}=3.58, \mathrm{df}=98)$. No significant difference exists in case of social relationships $(\mathrm{p}=.148, \mathrm{t}=1.494$, $\mathrm{df}=98)$. The physical health has a significant difference for wife and others $(\mathrm{p}=.007, \mathrm{t}=2.75, \mathrm{df}=98)$. Overall total caregivers burden differs significantly for wife and others $(\mathrm{p}=.010, \mathrm{t}=2.62, \mathrm{df}=98)$.

\section{Discussion:}

The study on caregivers of patients with alcohol use disorder has gained a lot of importance in the previous decade. Our study was different in the aspect of geography where the sample was collected from central India. Alcohol use disorder and caregiving have been discussed and the scale used to assess these have been validated at both national and international levels. In this century patient-centred treatment with an emphasis on family engagement and knowledge sharing about mental health has become evident as a significant idea. As families play a major role in the treatment of their relatives, having a deeper and better understanding of caregiver's burden becomes utmost necessary. (SAMHSA, 2010).

The Caregivers Burden Inventory (CBI) includes the following domains (i) Time-Dependence Burden, (ii) Developmental Burden, (iii) Physical Burden, (iv) Social Burden and (v) Emotional Burden. The domain emotional burden assesses the feelings caregivers have for the patients. The domain developmental burden assesses the degree to which caregivers feel left out as compared to their peers. The domain physical burden assesses the tiredness and feeling of fatigue caregivers 'experience. The domain timedependence assesses the impact caregiving has on the caregiver's time. The domain social burden assesses caregivers' feelings of imbalance in their work and family lives.

Caring for a family member with Alcohol Use Disorder has profound effects on the caregivers. Over the past two decades, there has been growing evidence that addiction is a disorder of brain. Addiction has societal implications that are not only detrimental but perceived as a moral failing as well. Substance abuse in India is not considered a disease but just a habit and carries a social stigma.

Our study compared the distribution of caregivers' burden with respect to the wife and other relations as assessed by CBI, the results reported a significant difference in the burden $(\mathrm{p}=.010 *)$.

Crisp et al. (2005) reported that patients with alcohol use disorder, drink without considering the future consequences, spend lavishly on alcohol not taking into consideration the emotional responses and the basic needs of family members. The caregiving experience is tempered by many factors, including caregivers' socio-demographic profile, support network, and physical resources. It is reasonable to assume that the caregiving burden can manifest in multiple ways. Shifren et al. (2009) in their study suggested that various aspects of marriage (psychological and social) can strongly protect against the development and progression of alcohol use disorder if other confounding factors like family history, antisocial personality traits, and socioeconomic status are eliminated. It is probably because the spouses were dependent on the patients for various reasons like finance and child-rearing. 
Caregiving experience is a lifelong process and addiction is a chronic relapsing disease that increases the burden of care. Little attention has been paid in the relationship between caregiver burden and alcohol use disorder. Our study provides evidence that caregivers' health is equally important and may serve as a fundamental for health and mental health service providers who treat caregivers'.

\section{Conclusion}

The purpose of the research was to examine the burden on caregivers of relatives with alcohol use disorder. Based on the structured questionnaire (CBI), the caregivers identified their perceptions of living with and/or caring for the relative. The finding of this research contribute to existing information about the burden of a caregiver of a person with alcohol use disorder. The roles that families play in the recovery and sobriety of a substance abuse relative is important. The burden caregivers themselves face while helping their first degree relatives is equally important as it needs to be contemplated not only for the sake of the caregiving individual but also the patient.

\section{Bibliography:}

1. Alcohol Alert originally appeared in the National Institute on Alcohol Abuse and Alcoholism (NIAAA) Five-Year Strategic Plan. The Plan is available online at http://pubs.niaaa.nih.gov/publications/Strategic Plan/niaaas trategicplan.htm

2. Alcohol consumption rising fast in India :OECD report. http://indianexpress.com/ article/ india/india-others/alcohol -consumption-risingfast-in-india-oecd-report/

3. American Psychiatric Association (2013) Diagnostic and Statistical Manual of Mental Disorders, 5th edn. (DSM-5). Arlington, VA: American Psychiatric Publishing.

4. Bialon LN, Coke S. A Study on Caregiver Burden: Stressors, Challenges, and Possible Solutions. American Journal of Hospice and Palliative Medicine®. 2012 May;29(3):210-8.
5. Collins SE, Kirouac M (2013). "Alcohol Consumption". Encyclopedia of Behavioral Medicine: 61-65. doi:10.1007/978-1-44191005-9_626.

6. Crisp A, Gelder M, Goddard E, Meltzer H. Stigmatization of people with mental illnesses: A follow-up study within the Changing Minds campaign of the Royal College of Psychiatrists. World Psychiatry. 2005;4:106113.

7. Crisp AH, Gelder MG, Rix S, Meltzer HI, Rowlands OJ. Stigmatisation of people with mental illnesses. British Journal of Psychiatry. 2000;177:4-7

8. Odlaug BL, Gual A, DeCourcy J, Perry R, Pike $\mathrm{J}$, Heron L, et al. Alcohol Dependence, Cooccurring Conditions and Attributable Burden. Alcohol and Alcoholism. 2016 Mar;51(2):2019.

9. Psychosocial Factors in Alcohol Use and Alcoholism. Retrived from https://pubs.niaaa.nih.gov/publications/10report /chap03c.pdf

10. Substance Abuse and Mental Health Services Administration (SAMHSA, 2010). Results from the 2010 NSDUH summary of findings. Available at http//:samhsa.gov/NSDUH Accessed on November 1, 2012.

11. Shifren K, editor. How caregiving affects development: psychological implications for child, adolescent, and adult caregivers. 1st ed. Washington, DC: American Psychological Association; 2009. 223 p.

12. What is a standard drink? retrieved from https://www.niaaa.nih.gov/alcohol-

health/overview-alcohol-consumption/whatstandard-drinkon October $7^{\text {th }} 2018$

13. WHO (1992) The ICD-10 Classification of Mental and Behavioural Disorders:Clinical Descriptions and Diagnostic Guidelines. Geneva: World Health Organization. 